\title{
The recent advances of phenotypes in acute exacerbations of COPD
}

\author{
This article was published in the following Dove Press journal: \\ International Journal of COPD \\ 27 March 2017 \\ Number of times this article has been viewed
}

\author{
Aiyuan Zhou ${ }^{1-3}$ \\ Zijing Zhoul-3 \\ Yiyang Zhaol-3 \\ Ping Chen ${ }^{1-3}$ \\ 'Department of Respiratory Medicine, \\ The Second Xiangya Hospital, \\ ${ }^{2}$ Research Unit of Respiratory \\ Disease, ${ }^{3}$ Diagnosis and Treatment \\ Center of Respiratory Disease, \\ Central South University, Changsha, \\ Hunan, People's Republic of China
}

\begin{abstract}
Exacerbations of COPD are clinically relevant events with therapeutic and prognostic implications. Yet, significant heterogeneity of clinical presentation and disease progression exists within acute exacerbations of COPD (AECOPD). Currently, different phenotypes have been widely used to describe the characteristics among patients with AECOPD. This has proved to be significant in the treatment and prediction of the outcomes of the disease. In this review of published literature, the phenotypes of AECOPD were classified according to etiology, inflammatory biomarkers, clinical manifestation, comorbidity, the frequency of exacerbations, and so on. This review concentrates on advancements in the use of phenotypes of AECOPD.
\end{abstract}

Keywords: COPD, acute exacerbation, phenotype, treatment, prognosis

\section{Abbreviations}

ACOS, asthma-COPD overlap syndrome; AECOPD, acute exacerbations of COPD; BODE, body mass index, airflow obstruction, dyspnea, and exercise capacity; CAT, COPD Assessment Test; CCQ, Clinical COPD Questionnaire; CRP, C-reactive protein; ECLIPSE, Evaluation of COPD Longitudinally to Identify Predictive Surrogate Endpoints; FeNO, fractional exhaled nitric oxide; $\mathrm{FEV}_{1}$, forced expiratory volume in 1 second; GesEPOC, Spanish COPD guidelines; GOLD, Global Initiative for Chronic Obstructive Lung Disease; 4-HNE, 4-human neutrophil elastase; ICS, inhaled corticosteroids; ICU, intensive care unit; IL-6, interleukin-6; MBL, mannose-binding lectin; MMP-9, matrix metalloproteinase-9; mMRC, modified medical research council; MPO, myeloperoxidase; NETT, National Emphysema Treatment Trial; PF4, platelet factor 4; PCT, procalcitonin; SAA, serum amyloid protein A; SP-D, serum surfactant protein-D; TNT, troponin-T; VEGF, vascular endothelial growth factor.

\section{Introduction}

AECOPD is an acute event characterized by a worsening of the patient's respiratory symptoms that is beyond normal day-to-day variation and leads to change in medication. ${ }^{1}$ At first glance, this definition seems straightforward. However, it has several caveats and unknowns that differ according to each patient's pathobiological heterogeneity and different clinical presentation and management needs.

COPD phenotype is defined as "a single or combination of disease attributes that describe differences between individuals with COPD as they relate to clinically meaningful outcomes". Therefore, the phenotype should be able to be used to classify patients into subgroups with a prognostic value that allows determining the best treatment in order to achieve better clinical results. ${ }^{2}$ In this way, we can take on a more personalized treatment according to the severity of the airflow obstruction and
Department of Respiratory Medicine,

The Second Xiangya Hospital, Central

South University, I 39 Renmin Middle

Road, Changsha, Hunan 4100II,

People's Republic of China

Tel +86 731 85295248

Email pingchen073I@csu.edu.cn (c) (1) (5) 2017 hhou et al. This work is published and licensed by Dove Medical Press Limited. The full terms of this license are available at https://www.dovepress.com/terms.php (c)
hereby accept the Terms. Non-commercial uses of the work are permitted without any further permission from Dove Medical Press Limited, provided the work is properly attributed. For permission for commercial use of this work, please see paragraphs 4.2 and 5 of our Terms (https://www.dovepress.com/terms.php).
s. 
conditioned by the clinical phenotype. Recent findings suggest that exacerbations of COPD are heterogeneous events and that this heterogeneity might have clinically relevant therapeutic and prognostic effects. ${ }^{3}$ In a viewpoint published in the journal The Lancet Respiratory Medicine, ${ }^{4}$ the authors proposed a two-axis classification of exacerbations of COPD by considering the pathobiological and clinical heterogeneity of exacerbations of COPD. They stratified patients into four groups (E1-E4), each of which might need a different treatment strategy and have a different short-term risk, and hence the need for a different care setting. Unfortunately, phenotype in AECOPD is still in a stage of exploration. It has always been classified based on different etiologies, clinical manifestations, biomarkers, comorbidities, frequencies of exacerbation, and so on. In this review, we mainly focus on the phenotypes that have been proven to have a therapeutic or prognostic effect on patients with AECOPD.

\section{Methods}

\section{Search strategy}

A review was performed to identify research articles or meta-analysis from 1986 to 2016 that assessed the characteristics, including etiology, manifestation, inflammatory cells, comorbidity, and frequency of exacerbation, which are related to different therapies or prognosis of patients with AECOPD. This review was performed on September 5, 2016, in PubMed. The search strategy is shown in Table 1.

\section{Eligibility criteria for study selection}

Studies including articles or meta-analysis that focused on any one of the characteristics associated with different therapies or prognosis of the patients with AECOPD were included. Patients must be subjects older than 40 years diagnosed with AECOPD. Articles were excluded if they did not show the different traits based on the phenotypes, subgroups, or heterogeneity. Studies that tested empirically defined phenotypes without an analytical justification of these phenotypes and those that concentrated on the phenotypes in stable

Table I Search strategy

\begin{tabular}{ll}
\hline PubMed strategy \\
\hline Step & Search terms \\
\hline$\# I$ & "Acute exacerbation of Chronic Obstructive \\
& Pulmonary Disease" [Mesh] \\
$\# 2$ & "Exacerbation of COPD" [Mesh] \\
$\# 3$ & $\# I$ OR \#2 \\
$\# 4$ & Phenotype[Text Word] OR subgroups[Text Word]OR \\
& heterogeneity[Text Word] OR different characteristic \\
$\# 5$ & [Text Word] \\
\hline
\end{tabular}

COPD were excluded. Moreover, the abstracts of the articles not published in English were excluded. Two independent authors (AZ and $\mathrm{ZZ}$ ) reviewed the title and abstract against the inclusion criteria. Disagreements between reviewers were resolved through the third reviewer by discussion.

\section{Etiology phenotypes}

It is well known that AECOPD may be triggered by infection with bacteria or viruses or by noninfectious environmental (eg, temperature, pollution, allergens, and diet) or internal (immune dysregulation) factors. The cause of approximately one-third of exacerbations cannot be identified. ${ }^{5-7}$ Patients with detectable respiratory pathogens have been shown to exhibit a more marked impact on lung function and longer duration of hospitalization than patients with exacerbations of noninfectious etiology. ${ }^{8}$ With in-depth studies of microorganisms, some research concludes that there are differences in the clinical manifestation, treatment, and prognosis between bacterial infections and viral infections. Sore throat, cough, dyspnea, and chills are more common in viral infections than in bacterial infections. ${ }^{9}$ Viral exacerbations are associated with higher IL-6 levels, ${ }^{10}$ lower levels of CRP, ${ }^{11}$ and longer duration of hospital stay (average 9 days). ${ }^{12}$ However, as for antiviral treatment, the current therapies for the virus-induced exacerbations are not very effective. ${ }^{12}$ The guideline about the lower respiratory tract infection treatment published in 2011 by the European Respiratory Society pointed out that AECOPD patients usually were not recommended to have empiric antiviral treatment. However, if in flu season, or at high risk of flu, patients with typical influenza symptoms (such as fever, muscle pain, muscle weakness, and respiratory infection symptoms), if onset is within 2 days, should have antiviral treatment as early as possible. ${ }^{13}$ In bacterial exacerbations, purulent sputum is the typical symptom, as is neutrophil inflammation in both blood and airway. Levels of CRP and PCT would be higher than those in non-bacterial exacerbations. ${ }^{14}$ Cited guidelines suggest that exacerbations of COPD with purulence of sputum are the most important symptom, which calls for the use of antibiotics. ${ }^{15,16}$ Altogether, knowing the characteristics of various etiologies may have important therapeutic implications and provide evidence for local surveillance of AECOPD pathogens and appropriate choice of antimicrobials. This may give clinicians some indications to avoid abusing antibiotics to some extent.

\section{Inflammatory phenotypes}

Patients with AECOPD also display heterogeneous inflammation. At present, the diagnosis of AECOPD mainly 
depends on clinical symptoms. There is lack of quantitative indicators. Inflammatory markers as a kind of quantitative indicator are widely used in judging acute exacerbation and assessing prognosis. Systemic inflammatory markers mainly include CRP, ${ }^{17-19}$ PCT, ${ }^{20,21}$ serum amyloid $\mathrm{A},{ }^{22}$ SP-D,${ }^{23}$ fibrinogen,${ }^{24}$ inflammation cell chemotactic factor ${ }^{25}$ and so on. All the markers mentioned earlier will increase in AECOPD patients and decrease in recovery. As a result of these investigations using biomarkers, the patients were divided into different phenotypes.

CRP is one of the most important biomarkers. A small study reported that a cutoff value of $19.65 \mathrm{mg} / \mathrm{L}$ has a sensitivity of $78 \%$ and a specificity of $84 \%$ to identify the bacterial origin of exacerbations of COPD. In patients with AECOPD with mucoid sputum, an elevated CRP level of $>15.21 \mathrm{mg} / \mathrm{L}$ indicates bacterial infection. ${ }^{18}$ However, a study published recently found that PCT and CRP cannot differentiate between bacterial and viral infections in the exacerbations of COPD requiring emergency department visits. ${ }^{26}$ Another study showed that CRP $>100 \mathrm{mg} / \mathrm{mL}$ was associated with a near fourfold increased probability of adverse outcome. ${ }^{27}$ PCT is also a very important marker in AECOPD. PCT level $>0.5 \mathrm{ng} / \mathrm{mL}$ is independently associated with bacterial isolation in severe AECOPD. ${ }^{21,28}$ In addition, in patients who required intubation and mechanical ventilation, PCT levels are independently associated with increased risk for ICU mortality. ${ }^{21}$ Yet, a post hoc analysis of a randomized, placebo-controlled trial that failed to show a positive effect of antibiotics in COPD exacerbations suggested that patients with low PCT concentrations during a COPD exacerbation might also benefit from antibiotic treatment. ${ }^{29}$ Above all, the results from a meta-analysis suggest that PCT-guided treatment can safely reduce antibiotic overuse in patients with AECOPD,${ }^{30}$ but the cutoff of PCT to use antibiotics has no consensus; further studies are needed to evaluate the utility of PCT measurement. ${ }^{31}$

Some biomarkers, such as fibrinogen, $,{ }^{32,33} \mathrm{TNT},{ }^{34} \mathrm{VEGF},{ }^{35}$ 4-HNE, ${ }^{36} \mathrm{PF} 4,{ }^{37} \beta$-thromboglobulin, ${ }^{38}$ and copeptin, ${ }^{19}$ may also reflect the severity of AECOPD and can be used as prognostic markers. However, there is no cut point enabling these markers to differentiate between patients with different phenotypes. In the period of AECOPD, the airway inflammation is more severe than that in stable COPD. The most widely used biomarkers of airway inflammation are FeNO and induced sputum analysis. Currently, FeNO is regarded as the most promising indicator. ${ }^{39}$ Some studies have reported that patients with high $\mathrm{FeNO}$ levels will have a good response to corticosteroids and greater improvement in $\mathrm{FEV}_{1}{ }^{39,40}$ The reason for this result may be due to the fact that the
FeNO level correlated well with the eosinophils, which is a good predictor for the response to corticosteroids..$^{41,42}$ Antus et $\mathrm{a}^{43}$ pointed out that the optimum cutoff point for FENO as a predictor for significant increase in $\mathrm{FEV}_{1}$ was $26.8 \mathrm{ppb}$ (sensitivity: $74 \%$ and specificity: $75 \%$ ). In addition, induced sputum analysis has beneficial effects on the treatment and prognosis of patients with AECOPD. Patients can be divided into different phenotypes according to the type of inflammatory cells. These inflammatory phenotypes are clinically relevant due to potential differences in the response to therapeutic interventions. Gao et $\mathrm{al}^{44}$ recently identified the following four subgroups: eosinophilic predominant, neutrophilic predominant, paucigranulocytic predominant, and mixed granulocytic predominant. The eosinophilic phenotype (EO) is so named when sputum eosinophils are $>2.5 \%$ of total cells, the neutrophilic phenotype (NE) is the subgroup having neutrophils $>61 \%$, the paucigranulocytic phenotype (PA) has eosinophils $\leq 2.5 \%$ and neutrophils $\leq 61 \%$, and the mixed granulocytic phenotype (MC) has eosinophils $>2.5 \%$ and neutrophils $>61 \%$. Different phenotypes have different pathological and physiological characteristics. The results of this study showed that the patients with mixed granulocytic or neutrophilic AECOPD had a higher BODE score, more sputum inflammatory cells, lower lung function, and longer hospital stay, accompanied by higher concentrations of sputum MMP-9, IL-6, and CRP and serum SAA, IL-6, and CRP. Notably, $83 \%$ of patients with neutrophilic AECOPD displayed evidence of bacterial infection and many of them responded poorly to standard therapies. Patients with EO, especially when combined with asthma, have a better response to corticosteroids than the rest of the other types. ${ }^{45}$ Similar results were later reported by Bafadhel et al. ${ }^{46}$ Therefore, the classification of inflammatory cells in sputum and the level of FeNO are of great importance in assessing the prognosis of patients and guiding whether or not to use corticosteroids. However, although the identification of inflammatory phenotype is meaningful for AECOPD, the sensitivity, specificity, and multiindex application of this method on the efficiency of the diagnosis remain to be further studied. ${ }^{47}$

\section{Clinical manifestation of phenotypes}

As mentioned earlier, AECOPD is a heterogeneous disease and this heterogeneity can also be reflected in the symptoms. In exacerbations, the most important symptoms are increased dyspnea, sputum volume, and sputum purulence. Nowadays, the recognized criterion used to classify AECOPD according to symptoms is the Anthonisen standard. ${ }^{48}$ Anthonisen et al ${ }^{48}$ divided exacerbations into three types. Type 1 exacerbations 
involve increased dyspnea, sputum volume, and sputum purulence, Type 2 involve any two of the latter symptoms, and Type 3 just involves one of those symptoms combined with cough, wheeze, or symptoms of an upper respiratory tract infection. In Type 1 exacerbations, patients had an improved response to the antibiotic therapy and the CRP level in Type 1 was more elevated than in the other two types. It is recommended that antibiotics are used as early as possible in Type 1 exacerbations. ${ }^{49}$ Moreover, Stockley et $\mathrm{al}^{50}$ found that the presence of green (purulent) sputum indicates a clear subset of patients identified at presentation who are likely to benefit most from antibiotic therapy. In addition, before an episode of exacerbation, the prodromes are different among patients. Aaron et $\mathrm{al}^{51}$ divided the exacerbations of COPD into two distinct patterns, such as sudden and gradual onsets, according to worsening respiratory symptoms from diary cards. Patients who experienced sudden onset exacerbations had greater mean daily symptom scores, greater peak symptom scores, earlier peak symptoms, and shorter median recovery times back to baseline health status. Above all, these prodromes are important in differentiating the triggers of exacerbations. For instance, dyspnea, common colds, sore throat, and cough increase significantly during the prodromal phase, indicating that the triggers are more likely to be viral. Colds are even associated with longer and more severe exacerbations, and there is no doubt that a COPD patient who develops a cold should be considered for early therapy. ${ }^{52}$

It is well known that the severity of COPD is assessed not only by lung function, but CAT, mMRC questionnaires, and CCQ also have great importance in assessing the disease severity and estimating the risk of exacerbations. In GOLD 2013, CAT and mMRC were used for grading and different grades corresponded to different treatments. ${ }^{53}$ According to the clinical manifestation of the phenotype, the clinician can therefore provide more purposeful and individualized treatment.

\section{Comorbidity phenotypes}

AECOPD is often accompanied by comorbidities, which include not only the pulmonary disease but also the extrapulmonary disease. Comorbidities during hospital admission are associated with increased length of stay, mortality, and poor outcomes in patients with AECOPD. ${ }^{54}$ In terms of the pulmonary comorbidity, it is very common to see a great number of patients who suffer COPD accompanied by asthma, ${ }^{55}$ pneumonia, ${ }^{56}$ and lung cancer. ${ }^{57}$ Patients having the characteristics that are attributed to both COPD and asthma are called mixed phenotypes. A study has shown that between
$20 \%$ and $40 \%$ of COPD patients can be carriers of a mixed phenotype. ${ }^{55}$ This newly described phenotype is called as the ACOS. ${ }^{58,59}$ Patients with a history of asthma are more likely to have a good response to corticosteroids, ${ }^{55}$ and the $\mathrm{FEV}_{1}$ decreased faster than that in patients who have no asthma. ${ }^{60}$ Furthermore, in GOLD 2014, bronchiectasis has been added to the comorbidities of COPD. Patients with the diagnosis of COPD who share the comorbidity of bronchiectasis will experience longer exacerbations. The pathogens in patients with AECOPD and bronchiectasis are complex and will usually need broad-spectrum antibiotics. ${ }^{61,62}$

COPD can no longer be considered as a disease, which only affects the lungs. Increasing evidence supports the presence of a systemic inflammatory component, which is thought to provide the link between COPD and other extrapulmonary comorbidities. ${ }^{63,64}$ These include cardiovascular disorders, skeletal muscle dysfunction, diabetes, osteoporosis, anxiety, and depression. ${ }^{65-68}$ Similarly, a multicenter Spanish study identified four COPD exacerbation types (subtypes A-D, classified on the basis of their clinical severity and presence or absence of comorbidities). Patients with these different subtypes of the disease required different hospital setting needs (regular ward vs intensive care unit): subtype A ( $\mathrm{n}=934)$, neither high comorbidity nor severe exacerbation; subtype B $(n=682)$, moderate comorbidities; subtype $C(n=562)$, severe comorbidities related to mortality; and subtype D $(n=309)$, very severe exacerbation significantly related to mortality and admission to an intensive care unit. Subtype D experienced the highest rate of mortality, admission to an intensive care unit, and need for noninvasive mechanical ventilation. This was closely followed by subtype C, while subtypes A and B were primarily related to other serious complications. Hospitalization rate was $>50 \%$ for all the subtypes, although significantly higher for subtypes $\mathrm{C}$ and $\mathrm{D}$ than for subtypes A and B. ${ }^{69}$ These results could help to identify characteristics in order to categorize AECOPD patients for more appropriate care. They could also help in assessing interventions and treatments in subgroups with poor evolution and outcomes.

\section{Frequent exacerbations phenotypes}

The frequency of AECOPD is variable among patients. Recently, a "frequent exacerbator" phenotype has been postulated and examined in clinical studies. The pathophysiology underlying the frequent exacerbations phenotype includes increased airway and systemic inflammation, dynamic lung hyperinflation, changes in lower airway bacterial colonization, increased susceptibility to viral infection, and increased 
risk from comorbid extra pulmonary diseases. However, as for the definition of frequent exacerbators, there is no uniform standard at present. Most clinical research defined frequent exacerbators as those having a greater number of exacerbations than the median of the study population every year, those needing a course of oral antibiotics or oral glucocorticoid therapy, or those who needed to be hospitalized twice a year because of acute exacerbations. ${ }^{70,71}$ In the ECLIPSE study of COPD exacerbation susceptibility, $\sim 20 \%$ of patients with GOLD stage II disease and as many as $47 \%$ of those with stage IV disease were classified as frequent exacerbators (defined as two or more exacerbations annually). A previous study has shown that patients with frequent exacerbations and those with infrequent exacerbations tended to remain in the same category of exacerbation frequency for the full 3 years of the study, although a few patients may have shifted from one category to another. ${ }^{70}$ This stability could suggest that the frequency of exacerbations is related to the susceptibilities of the patients. A recent review has concluded the possible reasons for the frequency of AECOPD. It concludes that high levels of inflammation, high susceptibility to viral infection and bacterial colonization, fast $\mathrm{FEV}_{1}$, functional decline, poor health care status, and worsened comorbidity will increase the risk of exacerbation. ${ }^{72}$ Moreover, other studies also pointed out some meaningful factors that are related to the frequency, as listed in Table 2. Patients with a history of frequent exacerbations have an increased rise in both systemic inflammation and airway inflammation, ${ }^{73,74}$ more rapid decline of lung function, worse quality of life, ${ }^{75}$ and higher mortality rates $^{76,77}$ compared to patients with infrequent exacerbations. However, the classification of these frequent exacerbations phenotype is based on clinical records and/or patient recall, and the history of exacerbations is provided by the patients themselves. It is therefore important to ask about the history of exacerbations in the clinical interview in order to identify patients who may require anti-inflammatory medication. The treatment recommended in GOLD is also different for frequent exacerbators, such as long-term inhalation of corticosteroids. Adopting anti-inflammatory and anti-infection treatments in frequent exacerbators may be nontherapeutic. In the summary of the GesEPOC, ${ }^{78}$ the frequent exacerbators are further divided into the following two types: those with emphysema predominant and those with chronic bronchitis predominant. The treatment for the two types is also different. For the emphysema phenotype, the basis of pharmacological treatment is long-acting bronchodilators, and in some cases with ICS. The bronchitis-predominant exacerbator patients may be treated with bronchodilators and ICS, and in contrast to exacerbators with emphysema, they respond to treatment with Roflumilast. Selected cases with frequent exacerbations may respond to long-term treatment with macrolides, ${ }^{79}$ and when ICS cannot be used, mucolytics may be effective in reducing exacerbations. ${ }^{80}$ However, another study shows that whatever the declining degree of lung function, it is recommended that patients with frequent exacerbations use ICS combined with bronchial relaxation, which can significantly reduce the number of exacerbations and improve the quality of life.$^{81}$ The use of ICS is still a hot topic that needs large-scale, randomized, double-blind, controlled studies in order to assess its effectiveness. In summary, the frequent exacerbation phenotype as a distinct phenotype is of great significance and clinicians could develop a professional treatment for these patients, which can be used for health economic purposes. ${ }^{82}$

\section{Discussion}

The literature relating to AECOPD phenotypes in this review mainly focuses on the significant heterogeneity among the patients. The Anthonisen standard ${ }^{48}$ based on clinical manifestations (published in 1987) was the most widely recognized classification in many studies and is thought to have clinical implications. Clinicians may speculate on the kind of etiology, draw up an individual therapy protocol, and also evaluate the prognosis of patients with AECOPD according to their clinical manifestations. In an in-depth study of microorganisms, a respiratory infectious phenotype was classified by Dai et $a l^{8}$ who found that respiratory infectious phenotypes are associated with a greater length of stay in hospital and greater severity of symptoms in AECOPD. However, this study did not check all the relevant factors or diseases associated with a prolonged stay in hospital, which therefore may have affected their results. Further investigation is needed to assess the clinical implication of this phenotype. In terms of inflammatory phenotype, two studies ${ }^{44,46}$ classified AECOPD patients with inflammatory cells or biomarkers. Nevertheless, there are some differences between the classifications; in the study conducted by Gao et $\mathrm{al},{ }^{44}$ the patients were sorted into four groups, including EO, NE, PA, and MC. They conclude that there are some differences among these groups. While another study ${ }^{46}$ used cluster analysis to classify the patients into bacteria, virus, and eosinophil groups based on biomarkers. In this study, they used two methods to investigate biomarkers in AECOPD. The first method used unbiased statistical tools, identified biological COPD exacerbation phenotypes, and characterized exacerbations into four biological clusters, while the second method 


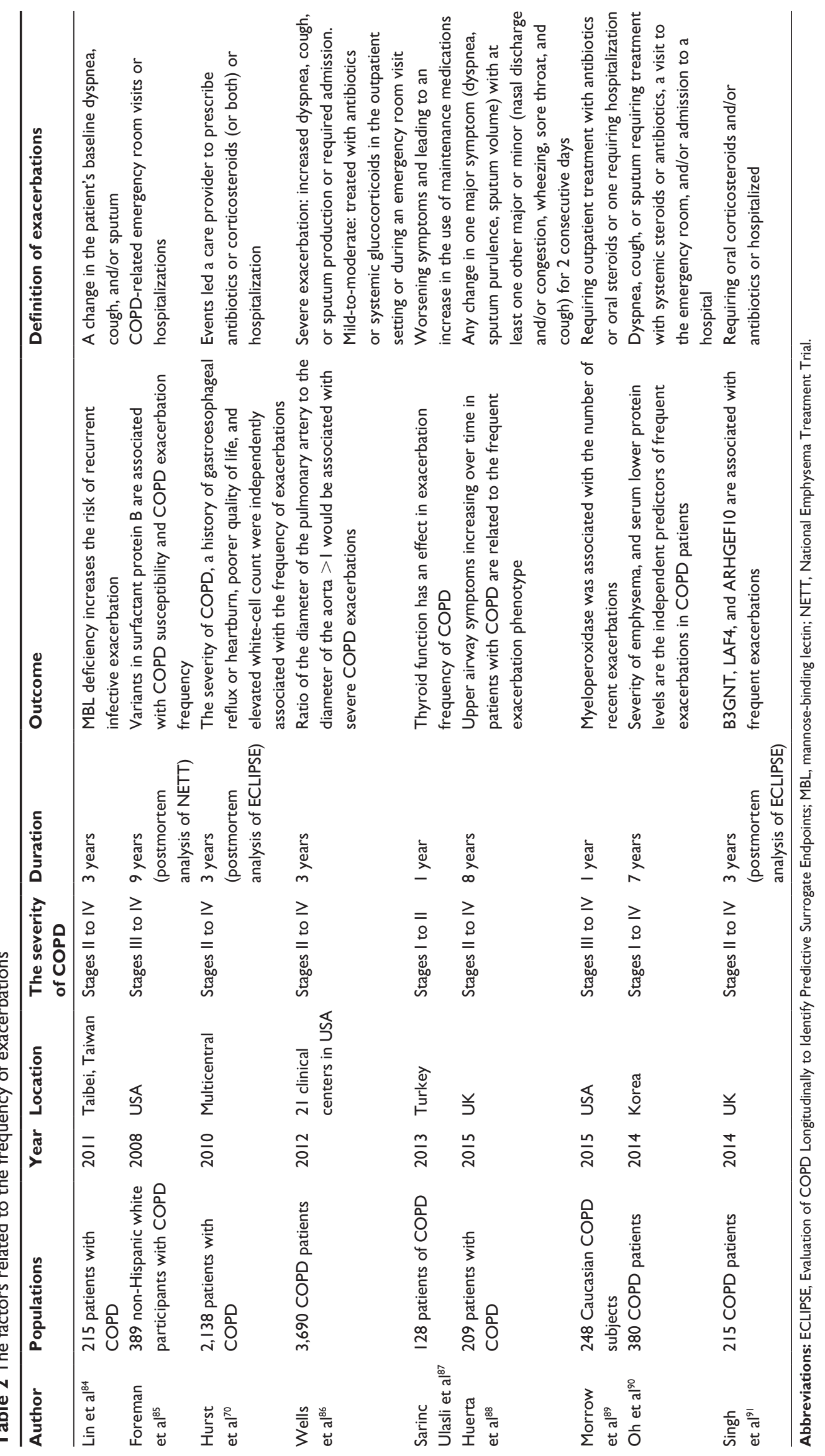


employed the currently used clinical exacerbation phenotypes of COPD related to potential etiology and inflammation (namely exacerbations that are associated with bacteria, virus, or a sputum eosinophilia). The biological exacerbation clusters were bacterial, viral, eosinophilic-predominant, and pauci-inflammatory. It was found that these clusters were remarkably similar to the clinical exacerbation phenotypes. Thus, in addition to identifying potential biomarkers to direct therapy and evaluate prognosis, these clinical exacerbation phenotypes are likely to represent distinct pathophysiological entities with specific biomarker signatures. In studies concerned with the comorbidity phenotype, Arostegui et $\mathrm{al}^{69}$ characterized the AECOPD patients into four types according to the severity of the current exacerbation and the comorbidities. Subtype D (defined as having very severe exacerbations with low or mild comorbidity) was significantly related to mortality and admission to an intensive care unit. Although this study did not offer detailed suggestions for the treatment of AECOPD, it evoked awareness in clinicians of the need to treat patients comprehensively. It was reported that the frequent exacerbations were related to many factors, as is well known. The current GOLD classification of COPD acknowledges the complexity of the disease, and the frequency of the exacerbation is also considered when classifying patients. It was suggested that patients with frequent exacerbations should have treatment with ICS. However, the definition of the frequent exacerbator and the subjects themselves varied among the studies. In a retrospective study, the frequency of the exacerbation could be influenced by the memory of the patients. In addition, there are some unreported exacerbations. Due to the difference in the frequency, the range of the patients who should be treated with ICS would be different too. Thus, in terms of the use of ICS, it requires large-scale, randomized, double-blind, controlled studies to gather more evidence supporting its use.

Limitations of our review include the following: the language restriction that articles not published in English were excluded in this review may induce a language bias. Moreover, the studies were extracted only from PubMed, which may result in missing some articles; nevertheless, we also make a simple glance over the articles related to the phenotypes of AECOPD in Web of Science and Embase, and there are no crucial studies that were not selected in the review. Another limitation is that we excluded studies that focused on the phenotypes in stable COPD. This may remove a potential phenotype from our review, which may also have prognostic value in the exacerbations of COPD. However, the exclusion was as per protocol, with the aim of producing a review, which is focused on answering a specific question related solely to AECOPD.

\section{Conclusion}

AECOPD is a heterogeneous disease. Investigations of the different phenotypes of AECOPD have resulted in the definition of different types of patients with prognostic and therapeutic significance. Because the diversity of the phenotypes of each condition is better understood, clinicians will be presented with opportunities to evolve from a "one size fits all" approach to personalized approaches, with the ultimate goal of improving care and reducing potential adverse effects from unnecessary therapies. ${ }^{83}$ However, research into AECOPD phenotypes is still in its infancy, and with a detailed study of the phenotypes of AECOPD, it is possible that a new phenotype allowing individualized treatment and estimation of prognosis will be found. This means that there is an urgent need for well-designed clinical studies focused on AECOPD phenotypes.

\section{Acknowledgment}

This study was supported by grants from the National Natural Science Foundation of China (NSFC; Grants 81370143 to Professor Ping Chen).

\section{Disclosure}

The authors report no conflicts of interest in this work.

\section{References}

1. Vestbo J, Hurd SS, Agusti AG, et al. Global strategy for the diagnosis, management, and prevention of chronic obstructive pulmonary disease: GOLD executive summary. Am J Respir Crit Care Med. 2013; 187(4):347-365.

2. Han MK, Agusti A, Calverley PM, et al. Chronic obstructive pulmonary disease phenotypes: the future of COPD. Am J Respir Crit Care Med. 2010;182(5):598-604.

3. Hurst JR. Exacerbation phenotyping in chronic obstructive pulmonary disease. Am J Respir Crit Care Med. 2011;184(6):625-626.

4. Lopez-Campos JL, Agusti A. Heterogeneity of chronic obstructive pulmonary disease exacerbations: a two-axes classification proposal. Lancet Respir Med. 2015;3(9):729-734.

5. Burge S, Wedzicha JA. COPD exacerbations: definitions and classifications. Eur Respir J Suppl. 2003;41:46s-53s.

6. Celli BR, Barnes PJ. Exacerbations of chronic obstructive pulmonary disease. Eur Respir J. 2007;29(6):1224-1238.

7. Beghe B, Verduri A, Roca M, Fabbri LM. Exacerbation of respiratory symptoms in COPD patients may not be exacerbations of COPD. Eur Respir J. 2013;41(4):993-995.

8. Dai MY, Qiao JP, Xu YH, Fei GH. Respiratory infectious phenotypes in acute exacerbation of COPD: an aid to length of stay and COPD Assessment Test. Int J Chron Obstruct Pulmon Dis. 2015;10(1):2257-2263.

9. Wedzicha JA, Donaldson GC. Exacerbations of chronic obstructive pulmonary disease. Respir Care. 2003;48(12):1204-1213; discussion 1213-1215.

10. Rohde G, Borg I, Wiethege A, et al. Inflammatory response in acute viral exacerbations of COPD. Infection. 2008;36(5):427-433. 
11. Garcha DS, Thurston SJ, Patel AR, et al. Changes in prevalence and load of airway bacteria using quantitative PCR in stable and exacerbated COPD. Thorax. 2012;67(12):1075-1080.

12. Dimopoulos G, Lerikou M, Tsiodras S, et al. Viral epidemiology of acute exacerbations of chronic obstructive pulmonary disease. Pulm Pharmacol Ther. 2012;25(1):12-18.

13. Woodhead M, Blasi F, Ewig S, et al; Joint Taskforce of the European Respiratory Society and European Society for Clinical Microbiology and Infectious Diseases. Guidelines for the management of adult lower respiratory tract infections - full version. Clin Microbiol Infect. 2011; 17 Suppl 6:E1-E59.

14. Tanriverdi H, Ornek T, Erboy F, et al. Comparison of diagnostic values of procalcitonin, C-reactive protein and blood neutrophil/lymphocyte ratio levels in predicting bacterial infection in hospitalized patients with acute exacerbations of COPD. Wien Klin Wochenschr. 2015;127 (19-20):756-763.

15. O'Donnell DE, Aaron S, Bourbeau J, et al. Canadian Thoracic Society recommendations for management of chronic obstructive pulmonary disease - 2007 update. Can Respir J. 2007;14 Suppl B:5B-32B.

16. Pauwels RA, Buist AS, Calverley PM, Jenkins CR, Hurd SS. Global strategy for the diagnosis, management, and prevention of chronic obstructive pulmonary disease. NHLBI/WHO Global Initiative for Chronic Obstructive Lung Disease (GOLD) workshop summary. Am J Respir Crit Care Med. 2001;163(5):1256-1276.

17. Karadeniz G, Polat G, Senol G, Buyuksirin M. C-reactive protein measurements as a marker of the severity of chronic obstructive pulmonary disease exacerbations. Inflammation. 2013;36(4):948-953.

18. Peng C, Tian C, Zhang Y, Yang X, Feng Y, Fan H. C-reactive protein levels predict bacterial exacerbation in patients with chronic obstructive pulmonary disease. Am J Med Sci. 2013;345(3):190-194.

19. Stolz D, Christ-Crain M, Morgenthaler NG, et al. Copeptin, C-reactive protein, and procalcitonin as prognostic biomarkers in acute exacerbation of COPD. Chest. 2007;131(4):1058-1067.

20. Corti C, Fally M, Fabricius-Bjerre A, et al. Point-of-care procalcitonin test to reduce antibiotic exposure in patients hospitalized with acute exacerbation of COPD. Int J Chron Obstruct Pulmon Dis. 2016;11: $1381-1389$

21. Rammaert B, Verdier N, Cavestri B, Nseir S. Procalcitonin as a prognostic factor in severe acute exacerbation of chronic obstructive pulmonary disease. Respirology. 2009;14(7):969-974.

22. Bozinovski S, Hutchinson A, Thompson M, et al. Serum amyloid a is a biomarker of acute exacerbations of chronic obstructive pulmonary disease. Am J Respir Crit Care Med. 2008;177(3):269-278.

23. Zien Alaabden A, Mohammad Y, Fahoum S. The role of serum surfactant protein $\mathrm{D}$ as a biomarker of exacerbation of chronic obstructive pulmonary disease. Qatar Med J. 2015;2015(2):18.

24. Wang S, Chen Y, Ren W, et al. 益气活血法对慢性阻塞性肺疾病 急性加重患者血浆纤维蛋白原及 D - 二聚体的影响 [Effect of Qi benefiting blood activating method on plasma fibrinogen and D-dimer in patients with acute exacerbation of chronic obstructive pulmonary disease]. Zhongguo Zhong Xi Yi Jie He Za Zhi. 2015;35(5):537-540. Chinese.

25. Papi A, Bellettato CM, Braccioni F, et al. Infections and airway inflammation in chronic obstructive pulmonary disease severe exacerbations. Am J Respir Crit Care Med. 2006;173(10):1114-1121.

26. Clark TW, Medina MJ, Batham S, Curran MD, Parmar S, Nicholson KG. C-reactive protein level and microbial aetiology in patients hospitalised with acute exacerbation of COPD. Eur Respir J. 2015;45(1):76-86.

27. Tofan F, Rahimi-Rad MH, Rasmi Y, Rahimirad S. High sensitive C-reactive protein for prediction of adverse outcome in acute exacerbation of chronic obstructive pulmonary disease. Pneumologia. 2012; 61(3):160-162.

28. Nseir S, Cavestri B, Di Pompeo C, et al. Factors predicting bacterial involvement in severe acute exacerbations of chronic obstructive pulmonary disease. Respiration. 2008;76(3):253-260.

29. Daniels JM, Schoorl M, Snijders D, et al. Procalcitonin vs C-reactive protein as predictive markers of response to antibiotic therapy in acute exacerbations of COPD. Chest. 2010;138(5):1108-1115.
30. Lin C, Pang Q. Meta-analysis and systematic review of procalcitoninguided treatment in acute exacerbation of chronic obstructive pulmonary disease. Clin Respir J. Epub 2016 Jun 22.

31. Zhang L, Huang J, Xu T, Lin Y. 降钙素原指导抗生素治疗策略 在社区获得性下呼吸道感染巾应用的荟萃分析 [Procalcitoninguided algorithms of antibiotic therapy in community-acquired lower respiratory tract infections: a systematic review and meta-analysis of randomized controlled trials]. Zhonghua Jie He He Hu Xi Za Zhi. 2012;35(4):275-282. Chinese.

32. Groenewegen KH, Postma DS, Hop WC, et al. Increased systemic inflammation is a risk factor for COPD exacerbations. Chest. 2008; 133(2):350-357.

33. Wedzicha JA, Seemungal TA, MacCallum PK, et al. Acute exacerbations of chronic obstructive pulmonary disease are accompanied by elevations of plasma fibrinogen and serum IL-6 levels. Thromb Haemost. 2000;84(2):210-215.

34. Hoiseth AD, Neukamm A, Karlsson BD, Omland T, Brekke PH, Soyseth V. Elevated high-sensitivity cardiac troponin T is associated with increased mortality after acute exacerbation of chronic obstructive pulmonary disease. Thorax. 2011;66(9):775-781.

35. Valipour A, Schreder M, Wolzt M, et al. Circulating vascular endothelial growth factor and systemic inflammatory markers in patients with stable and exacerbated chronic obstructive pulmonary disease. Clin Sci (Lond). 2008;115(7):225-232.

36. Liu H, Xu JY. 4一羟基壬烯醛在慢性阻塞性肺疾病严重程度评估 中的作用 [The role of 4-hydroxynonenal in assessment of chronic obstructive pulmonary disease severity]. Zhonghua Jie He He Hu Xi Za Zhi. 2012;35(10):758-761. Chinese.

37. Wu JF, Yang YH, Pang BS. 慢性阻塞性肺疾病急性加重 患者血浆血小板因子 4 及 13 凝血球蛋白水平的变化及其意 义 [Platelet factor 4 and beta-thromboglobulin in blood plasma of patients with acute exacerbation of chronic obstructive pulmonary disease]. Zhonghua Yi Xue Za Zhi. 2013;93(18): 1378-1382. Chinese.

38. Karadag F, Karul AB, Cildag O, Yilmaz M, Ozcan H. Biomarkers of systemic inflammation in stable and exacerbation phases of COPD. Lung. 2008;186(6):403-409.

39. Dummer JF, Epton MJ, Cowan JO, et al. Predicting corticosteroid response in chronic obstructive pulmonary disease using exhaled nitric oxide. Am J Respir Crit Care Med. 2009;180(9):846-852.

40. Kunisaki KM, Rice KL, Janoff EN, Rector TS, and Niewoehner DE. Exhaled nitric oxide, systemic inflammation, and the spirometric response to inhaled fluticasone propionate in severe chronic obstructive pulmonary disease: a prospective study. Ther Adv Respir Dis. 2008;2(2):55-64.

41. Amin K, Janson C, Bystrom J. Role of eosinophil granulocytes in allergic airway inflammation endotypes. Scand J Immunol. 2016;84(2): $75-85$.

42. Donohue JF, Herje N, Crater G, Rickard K. Characterization of airway inflammation in patients with COPD using fractional exhaled nitric oxide levels: a pilot study. Int J Chron Obstruct Pulmon Dis. 2014;9: 745-751.

43. Antus B, Barta I, Horvath I, Csiszer E. Relationship between exhaled nitric oxide and treatment response in COPD patients with exacerbations. Respirology. 2010;15(3):472-477.

44. Gao P, Zhang J, He X, Hao Y, Wang K, Gibson PG. Sputum inflammatory cell-based classification of patients with acute exacerbation of chronic obstructive pulmonary disease. PLoS One. 2013;8(5):e57678.

45. van Veen IH, Ten Brinke A, Gauw SA, Sterk PJ, Rabe KF, Bel EH. Consistency of sputum eosinophilia in difficult-to-treat asthma: a 5-year follow-up study. J Allergy Clin Immunol. 2009;124(3):615-617, 617.e1-617.e2.

46. Bafadhel M, McKenna S, Terry S, et al. Acute exacerbations of chronic obstructive pulmonary disease: identification of biologic clusters and their biomarkers. Am J Respir Crit Care Med. 2011;184(6):662-671.

47. Lacoma A, Prat C, Andreo F, et al. Value of procalcitonin, C-reactive protein, and neopterin in exacerbations of chronic obstructive pulmonary disease. Int J Chron Obstruct Pulmon Dis. 2011;6:157-169. 
48. Anthonisen NR, Manfreda J, Warren CP, Hershfield ES, Harding GK, Nelson NA. Antibiotic therapy in exacerbations of chronic obstructive pulmonary disease. Ann Intern Med. 1987;106(2):196-204.

49. Stolz D, Christ-Crain M, Bingisser R, et al. Antibiotic treatment of exacerbations of COPD: a randomized, controlled trial comparing procalcitonin-guidance with standard therapy. Chest. 2007;131(1):9-19.

50. Stockley RA, O'Brien C, Pye A, Hill SL. Relationship of sputum color to nature and outpatient management of acute exacerbations of COPD. Chest. 2000;117(6):1638-1645.

51. Aaron SD, Donaldson GC, Whitmore GA, Hurst JR, Ramsay T, Wedzicha JA. Time course and pattern of COPD exacerbation onset. Thorax. 2012;67(3):238-243.

52. Wedzicha JA, Seemungal TA. COPD exacerbations: defining their cause and prevention. Lancet. 2007;370(9589):786-796.

53. Masoompour SM, Mohammadi A, Mahdaviazad H. Adherence to the Global initiative for chronic obstructive lung disease guidelines for management of COPD: a hospital-base study. Clin Respir J. 2016;10(3): 298-302.

54. Almagro P, Cabrera FJ, Diez J, et al. Comorbidities and short-term prognosis in patients hospitalized for acute exacerbation of COPD: the EPOC en servicios de medicina interna (ESMI) study. Chest. 2012; 142(5):1126-1133.

55. Miravitlles M, Calle M, Soler-Cataluna JJ. Clinical phenotypes of COPD: identification, definition and implications for guidelines. Arch Bronconeumol. 2012;48(3):86-98.

56. Huerta A, Crisafulli E, Menendez R, et al. Pneumonic and nonpneumonic exacerbations of COPD: inflammatory response and clinical characteristics. Chest. 2013;144(4):1134-1142.

57. Roca M, Roca IC, Mihaescu T. Lung cancer - a comorbidity in chronic obstructive pulmonary disease. Rev Med Chir Soc Med Nat Iasi. 2012; 116(4):1055-1062.

58. Barrecheguren M, Esquinas C, Miravitlles M. The asthma-chronic obstructive pulmonary disease overlap syndrome (ACOS): opportunities and challenges. Curr Opin Pulm Med. 2015;21(1):74-79.

59. Adubato S, Menacker M. ACOs and the future of medicine: an interview with Morey Menacker, DO. MD Advis. 2014;7(2):4-6.

60. Zeki AA, Schivo M, Chan A, Albertson TE, Louie S. The asthma-COPD overlap syndrome: a common clinical problem in the elderly. J Allergy (Cairo). 2011;2011:861926.

61. Martinez-Garcia MA, de la Rosa Carrillo D, Soler-Cataluna JJ, et al. Prognostic value of bronchiectasis in patients with moderate-to-severe chronic obstructive pulmonary disease. Am J Respir Crit Care Med. 2013; 187(8):823-831

62. Chen YH, Sun YC. Bronchiectasis as a comorbidity of chronic obstructive pulmonary disease: implications and future research. Chin Med J (Engl). 2016;129(17):2017-2019.

63. MacNee W. Systemic inflammatory biomarkers and co-morbidities of chronic obstructive pulmonary disease. Ann Med. 2013;45(3):291-300.

64. Laratta CR, van Eeden S. Acute exacerbation of chronic obstructive pulmonary disease: cardiovascular links. Biomed Res Int. 2014; 2014:528789.

65. Fabbri LM, Luppi F, Beghe B, Rabe KF. Complex chronic comorbidities of COPD. Eur Respir J. 2008;31(1):204-212.

66. Soriano JB, Visick GT, Muellerova H, Payvandi N, Hansell AL. Patterns of comorbidities in newly diagnosed COPD and asthma in primary care. Chest. 2005;128(4):2099-2107.

67. Dodd JW, Charlton RA, van den Broek MD, Jones PW. Cognitive dysfunction in patients hospitalized with acute exacerbation of COPD. Chest. 2013;144(1):119-127.

68. Mannino DM, Thorn D, Swensen A, Holguin F. Prevalence and outcomes of diabetes, hypertension and cardiovascular disease in COPD. Eur Respir J. 2008;32(4):962-969.

69. Arostegui I, Esteban C, Garcia-Gutierrez S, et al. Subtypes of patients experiencing exacerbations of COPD and associations with outcomes. PLoS One. 2014;9(6):e98580.

70. Hurst JR, Vestbo J, Anzueto A, et al. Susceptibility to exacerbation in chronic obstructive pulmonary disease. $N$ Engl J Med. 2010; 363(12):1128-1138.
71. Tashkin DP. Frequent exacerbations of chronic obstructive pulmonary disease - a distinct phenotype? N Engl J Med. 2010;363(12): 1183-1184.

72. Wedzicha JA, Brill SE, Allinson JP, Donaldson GC. Mechanisms and impact of the frequent exacerbator phenotype in chronic obstructive pulmonary disease. BMC Med. 2013;11:181.

73. Donaldson GC, Seemungal TA, Patel IS, et al. Airway and systemic inflammation and decline in lung function in patients with COPD. Chest. 2005;128(4):1995-2004.

74. Bhowmik A, Seemungal TA, Sapsford RJ, Wedzicha JA. Relation of sputum inflammatory markers to symptoms and lung function changes in COPD exacerbations. Thorax. 2000;55(2):114-120.

75. Seemungal TA, Wilkinson TM, Hurst JR, Perera WR, Sapsford RJ, Wedzicha JA. Long-term erythromycin therapy is associated with decreased chronic obstructive pulmonary disease exacerbations. Am J Respir Crit Care Med. 2008;178(11):1139-1147.

76. Garcia-Aymerich J, Farrero E, Felez MA, et al. Risk factors of readmission to hospital for a COPD exacerbation: a prospective study. Thorax. 2003;58(2):100-105.

77. Soler-Cataluna JJ, Rodriguez-Roisin R. Frequent chronic obstructive pulmonary disease exacerbators: how much real, how much fictitious? COPD. 2010;7(4):276-284.

78. Miravitlles M, Soler-Cataluna JJ, Calle M, et al. A new approach to grading and treating COPD based on clinical phenotypes: summary of the Spanish COPD guidelines (GesEPOC). Prim Care Respir J. 2013; 22(1):117-121.

79. Albert RK, Connett J, Bailey WC, et al. Azithromycin for prevention of exacerbations of COPD. N Engl J Med. 2011;365(8):689-698.

80. Poole PJ, Black PN. Mucolytic agents for chronic bronchitis or chronic obstructive pulmonary disease. Cochrane Database Syst Rev. 2006;3: CD001287.

81. Ferguson GT, Anzueto A, Fei R, Emmett A, Knobil K, Kalberg C. Effect of fluticasone propionate/salmeterol (250/50 microg) or salmeterol (50 microg) on COPD exacerbations. Respir Med. 2008;102(8): 1099-1108.

82. Hoogendoorn M, Feenstra TL, Hoogenveen RT, Al M, Molken MR. Association between lung function and exacerbation frequency in patients with COPD. Int J Chron Obstruct Pulmon Dis. 2010;5: 435-444.

83. Carolan BJ, Sutherland ER. Clinical phenotypes of chronic obstructive pulmonary disease and asthma: recent advances. J Allergy Clin Immunol. 2013;131(3):627-634; quiz 635.

84. Lin CL, Siu LK, Lin JC, et al. Mannose-binding lectin gene polymorphism contributes to recurrence of infective exacerbation in patients with COPD. Chest. 2011;139(1):43-51.

85. Foreman MG, DeMeo DL, Hersh CP, et al. Polymorphic variation in surfactant protein B is associated with COPD exacerbations. Eur Respir J. 2008;32(4):938-944.

86. Wells JM, Washko GR, Han MK, et al. Pulmonary arterial enlargement and acute exacerbations of COPD. N Engl J Med. 2012;367(10):913-921.

87. Sarinc Ulasli S, Bozbas SS, Ozen ZE, Ozyurek BA, Ulubay G. Effect of thyroid function on COPD exacerbation frequency: a preliminary study. Multidiscip Respir Med. 2013;8(1):64.

88. Huerta A, Donaldson GC, Singh R, et al. Upper respiratory symptoms worsen over time and relate to clinical phenotype in chronic obstructive pulmonary disease. Ann Am Thorac Soc. 2015;12(7):997-1004.

89. Morrow JD, Qiu W, Chhabra D, et al. Identifying a gene expression signature of frequent COPD exacerbations in peripheral blood using network methods. BMC Med Genomics. 2015;8:1.

90. Oh YM, Sheen SS, Park JH, et al. Emphysematous phenotype is an independent predictor for frequent exacerbation of COPD. Int J Tuberc Lung Dis. 2014;18(12):1407-1414.

91. Singh D, Fox SM, Tal-Singer R, Bates S, Riley JH, Celli B. Altered gene expression in blood and sputum in COPD frequent exacerbators in the ECLIPSE cohort. PLoS One. 2014;9(9):e107381. 
International Journal of COPD

Dovepress

\section{Publish your work in this journal}

The International Journal of COPD is an international, peer-reviewed journal of therapeutics and pharmacology focusing on concise rapid reporting of clinical studies and reviews in COPD. Special focus is given to the pathophysiological processes underlying the disease, intervention programs, patient focused education, and self management protocols.

This journal is indexed on PubMed Central, MedLine and CAS. The manuscript management system is completely online and includes a very quick and fair peer-review system, which is all easy to use. Visit http://www.dovepress.com/testimonials.php to read real quotes from published authors.

Submit your manuscript here: http://www.dovepress.com/international-journal-of-chronic-obstructive-pulmonary-disease-journal 